\title{
Interaction of the reduced species of 1,4-benzoquinone with alkylated cytosine and guanine nucleobases
}

\author{
Magali Salas, Bárbara Gordillo, and Felipe J. González* \\ Departamento de Química del Centro de Investigación y Estudios Avanzados, Av. Instituto \\ Politécnico Nacional 2508, Apdo. Postal 14-740, C. P. 07360, México D. F., Mexico \\ E-mail: fgonzale@cinvestav.mx
}

\begin{abstract}
Dedicated to Professor Eusebio Juaristi on the occasion of his $55^{\text {th }}$ anniversary
(received 15 Mar 05; accepted 02 May 05; published on the web 04 May 05)
\end{abstract}

\begin{abstract}
The interaction of the reduced species of 1,4-benzoquinone (Q) in the presence of 1octylcytosine and 9-ethylguanine has been studied in dimethylsulfoxide on glassy carbon electrodes. The electrochemical behavior showed that the semiquinone $\left(\mathrm{Q}^{{ }^{-}}\right)$and the quinone dianion $\left(\mathrm{Q}^{2-}\right)$ interact with 1-octylcytosine $(\mathrm{CH})$ according to a mechanism which involves only hydrogen bonding process. Contrasting with this mechanism, the nucleobase 9-ethylguanine $(\mathrm{GH})$ leads to protonation of the semiquinone or the dianion, depending on the time scale of the voltammetric experiment. The 9-ethylguanine anion $\left(\mathrm{G}^{-}\right)$, formed in the proton transfer reactions, activates a homogeneous chain mechanism giving rise to the spontaneous redox consumption of benzoquinone and the radical consumption of the 9-ethylguanine.
\end{abstract}

Keywords: 1-Octylcytosine, 9-ethylguanine, hydrogen bonding, 1,4-benzoquinone reduction

\section{Introduction}

The quinones are a special group of carbonylic compounds which act as electron and proton carriers in biochemical processes such as the photosynthesis and the oxidative phosphorylation of ADP to ATP. ${ }^{1,2}$ In these processes, the ATP formation is thermodynamically favored as a consequence of the electronic transfer by the quinones and other molecules. ${ }^{3}$ Regarding to these functions, hydrogen bonding plays an important role in the stabilization of the reduced species of quinones. ${ }^{4}$ It has been recognized also that the presence of the quinone nucleus and the nature of the substituents are both essential to develop cytotoxic and antineoplastic activity on the cells..$^{5-8}$ Thus, when the quinone is substituted with an appropriate alkyl chain, the compound can exhibit anticancer and antitumor activity. ${ }^{9,10}$ In this context it has been demonstrated that quinones react with the nucleobases of the DNA chain to generate a modified-DNA strand, which is not capable 
of replication. ${ }^{11}$ In particular, it has been found that photo and electrogenerated quinone derivatives interact with the nucleobases of DNA; however, details of the mechanism of this interaction are unknown. ${ }^{12-14}$ From an electrochemical point of view, we studied recently the mechanism by which the interaction between the reduction products of 1,4-benzoquinone with the alkylated nucleobases of thymine and adenine takes place. ${ }^{15}$ Therefore, considering that the reduced species of the quinone are able to interact with any nucleobase of DNA, in this work, we examine the interaction mechanisms between electrogenerated species of 1,4-benzoquinone (Q) with the complementary alkylated nucleobases 1-octylcytosine $(\mathrm{CH})$ and 9-ethylguanine (GH). It was anticipated that the amine functional groups of 1-octylcytosine (-NH) and 9-ethylguanine ($\mathrm{NH},-\mathrm{NH}_{2}$ ) interact with the reduced species of $\mathrm{Q}$ through strong hydrogen bonding interactions and/or proton transfer reactions.<smiles>O=C1C=CC(=O)C=C1</smiles>

Q<smiles>CC(C)n1ccc(N)nc1=O</smiles>

CH<smiles>CCn1cnc2c(=O)[nH]c(N)nc21</smiles>

GH

\section{Results and Discussion}

Electrochemical reduction of 1,4-benzoquinone $(\mathrm{Q})$ in the presence of 1-octylcytosine (CH) The electrochemical reduction of Q was studied in DMSO in the presence of $\mathrm{CH}$ at different concentrations. Figure 1a shows the voltammogram, obtained in aprotic medium, which shows typical oxido-reduction waves (I-II and III-IV), which correspond to the redox pairs Q/Q. ${ }^{-}$and $\mathrm{Q}^{-}{ }^{-} / \mathrm{Q}^{2-}$ respectively (eqs. 1 and 2 ). ${ }^{16,17}$

$$
\begin{gathered}
\mathrm{Q}+\mathrm{e}^{-} \underset{\mathrm{k}_{\mathrm{s} 1} \alpha_{1}}{\stackrel{\mathrm{E}^{\mathrm{o}}{ }_{1}}{\rightleftharpoons}} \mathrm{Q}^{--} \\
\mathrm{Q}^{\cdot-}+\mathrm{e}^{-} \underset{\mathrm{k}_{\mathrm{s} 2} \alpha_{2}}{\frac{\mathrm{E}^{\mathrm{o}}{ }_{2}}{\rightleftharpoons}} \mathrm{Q}^{2-}
\end{gathered}
$$




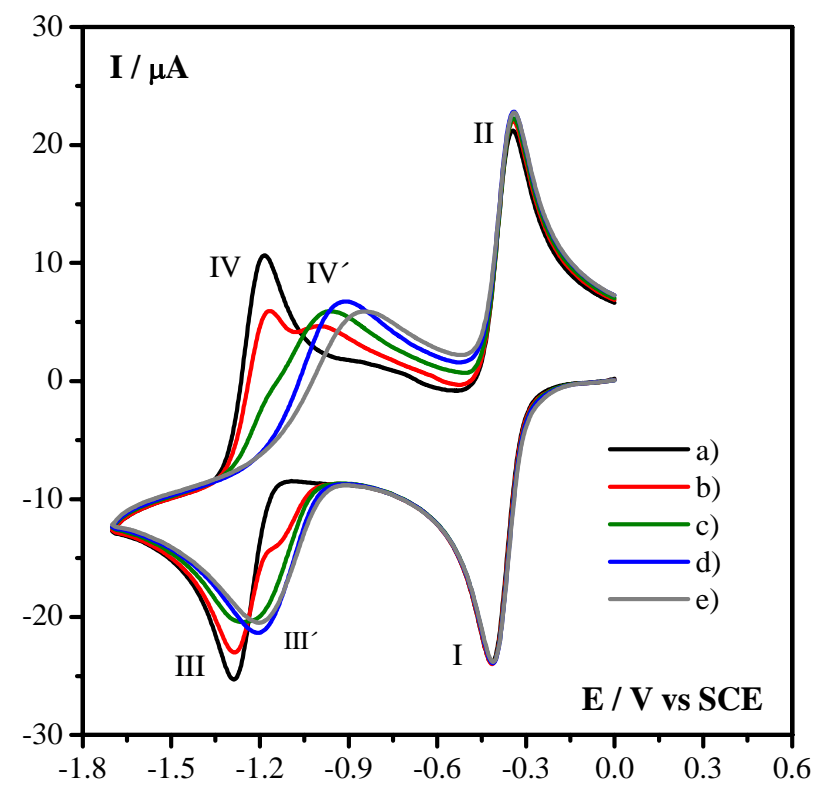

Figure 1. Cyclic voltammetry of 1,4-benzoquinone $2 \mathrm{mM}$, in $\mathrm{DMSO}+0.2 \mathrm{M} \mathrm{n}-\mathrm{Bu}_{4} \mathrm{NPF}_{6}$, on glassy carbon electrode ( $3 \mathrm{~mm} \phi$ ), at $0.1 \mathrm{Vs}^{-1}$, at different concentrations of 1-octylcytosine: a) 0 $\mathrm{mM}$, b) $0.8 \mathrm{mM}$, c) $2 \mathrm{mM}$, d) $6 \mathrm{mM}$, e) $18 \mathrm{mM}$.

When an excess of $\mathrm{CH}$ is present in the solution of Q (Figure 1e), it was observed that the chemical reversibility of waves I-II and III'-IV' is maintained, and this finding discards the intervention of any proton transfer reaction between the nucleobase $\mathrm{CH}$ and both the semiquinone $\mathrm{Q}^{-}$and the dianion $\mathrm{Q}^{2-} \cdot{ }^{16,18,19}$ It was also observed that in the accessible potential scale, the position of wave I-II is only marginally modified, whereas the wave III-IV is clearly shifted toward less negative potentials (III'-IV'). These results can be interpreted in terms of the intervention of hydrogen bonding association between $\mathrm{CH}$ and the reduced species $\mathrm{Q}^{-}$and $\mathrm{Q}^{2-}$ (eqs. 3 and 4). ${ }^{20-22}$ The interaction is probably taking place between the amino group of $\mathrm{CH}$ and the negatively charged oxygen of $\mathrm{Q}^{-}$and $\mathrm{Q}^{2-}$. Particularly, this kind of interaction stabilizes the negative charge of $\mathrm{Q}^{2-}$ and makes the redox process $\mathrm{Q}^{-} / \mathrm{Q}^{2-}$ energetically more favorable, that is presenting less negative reduction potentials; $\mathrm{E}_{1 / 2}(\mathrm{III}-\mathrm{IV})<\mathrm{E}_{1 / 2}(\mathrm{III}$ '-IV').

$$
\begin{array}{ll}
\mathrm{Q}^{--}+\mathbf{C H} & \stackrel{\mathrm{K}_{3}=\mathrm{k}_{3} / \mathrm{k}_{-3}}{\rightleftharpoons} \mathrm{Q}^{\cdot-}(\mathbf{C H}) \\
\mathrm{Q}^{2-}+\mathbf{C H} & \stackrel{\mathrm{K}_{4}=\mathrm{k}_{4} / \mathrm{k}_{-4}}{=} \mathrm{Q}^{2-}(\mathbf{C H})
\end{array}
$$

Considering that the shift of wave I-II $\left(\mathrm{Q} / \mathrm{Q}^{-}\right)$is only marginally significant, it can be proposed that the association of $\mathrm{Q}^{-}{ }^{-}$with $\mathrm{CH}$ is very weak. This equilibrium could be in principle neglected; however, it plays an important role in the global mechanism of electron transfer and association processes. 
Concerning the formation of the dianion $\left(\mathrm{Q}^{\cdot{ }^{-}} / \mathrm{Q}^{2-}\right)$, the large shift observed between waves III-IV and III'-IV', point out to a very strong hydrogen bonding association between $\mathrm{Q}^{2-}$ and $\mathrm{CH}^{18}$ Supporting this proposal, the appearance of prewave III'-IV' at $[\mathrm{CH}] /[\mathrm{Q}] \leq 1$ (Figure $1 \mathrm{~b}$ c), indicates that the reduction of $\mathrm{Q}^{-}$affords a fraction of free $\mathrm{Q}^{2-}$ and a complementary fraction of a strongly associated species $\mathrm{Q}^{2-}(\mathrm{CH})$, whose voltammetric formation wave III' is limited by the diffusion-controlled availability of $\mathrm{CH}^{18}{ }^{18}$ Additionally, in Figure 1 it is also observed that the

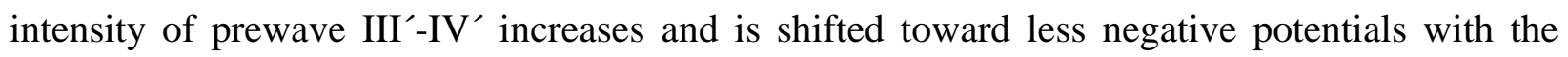
increase in the concentration of $\mathrm{CH}$. This behavior is indicative of a second association process occurring between the complex $\mathrm{Q}^{2-}(\mathrm{CH})$ and $\mathrm{CH}$, which affords the complex $\mathrm{Q}^{2-}(\mathrm{CH})_{2}$ (eq. $5) .{ }^{15,18}$ The proposal of this 1:2 complex appears likely in view of the fact that the quinone dianion contains two negative oxygen atoms with which the hydrogen bonding interactions with $\mathrm{CH}$ can occur. Because of steric hindrance, higher association stoichiometries are less likely.

$$
\mathrm{Q}^{2-}(\mathbf{C H})+\mathbf{C H} \stackrel{\mathrm{K}_{5}=\mathrm{k}_{5} / \mathrm{k}_{-5}}{=} \mathrm{Q}^{2-}(\mathbf{C H})_{2}
$$

Once the sequence of reactions 1-5 had been established, we performed a voltammetric simulation to establish the thermodynamics and kinetics of the electron transfer and association processes. ${ }^{18}$ In this way, the simulation of several experimental voltammograms obtained at different concentrations of $\mathrm{CH}$, was carried out with the program DigiSim V 2.1, (Bioanalytical Systems Inc.). ${ }^{23}$ The sequence of reactions given by the equations 1, 2, 4 and 5 was initially assumed as the operating mechanism; however the fitting between the simulated and experimental curves was not satisfactory. This result implicates that the sequence proposed, does not take into account other processes that could also participate in the global mechanism. Thus, considering that several electron transfer and associations processes have been described by means of reaction square schemes, ${ }^{24,25}$ in the present case we advance an alternative $3 \times 3$ reaction scheme (Scheme 1), which includes the association of semiquinone (eq. 3) and the reduction of the resulting complex arising from association (eq. 6, in Scheme 1).

Considering that the interaction between $\mathrm{Q}^{-}$and $\mathrm{CH}$ is very weak, it is expected that the association processes conducing to the complexes $\mathrm{Q}(\mathrm{CH}), \mathrm{Q}(\mathrm{CH})_{2}$, and $\mathrm{Q}^{-}(\mathrm{CH})_{2}$ is even weaker. The voltammetric simulation of the reduction and association processes, discarding these equilibria, was performed according to the mechanism indicated into the dotted lines of the diagram in Scheme 1. 


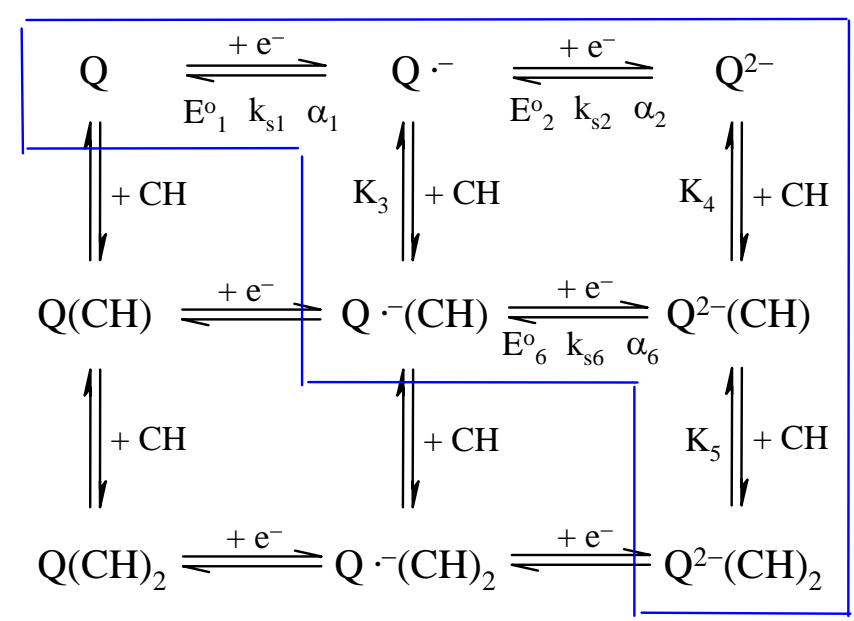

Scheme 1. Proposed mechanism of reduction and association in the electrochemical reduction of 1,4-benzoquinone $(\mathrm{Q})$ in the presence of 1-octylcytosine $(\mathrm{CH})$.

By using this approximation, some experimental voltammograms were simulated. Figure 2 shows the good agreement found between the experimental and simulated voltammograms at different concentrations of $\mathrm{CH}$. In this way, the principal thermodynamic and kinetic parameters, which allow the description of the experimental voltammograms, are shown in Table 1 and they must correspond closely to the real values.
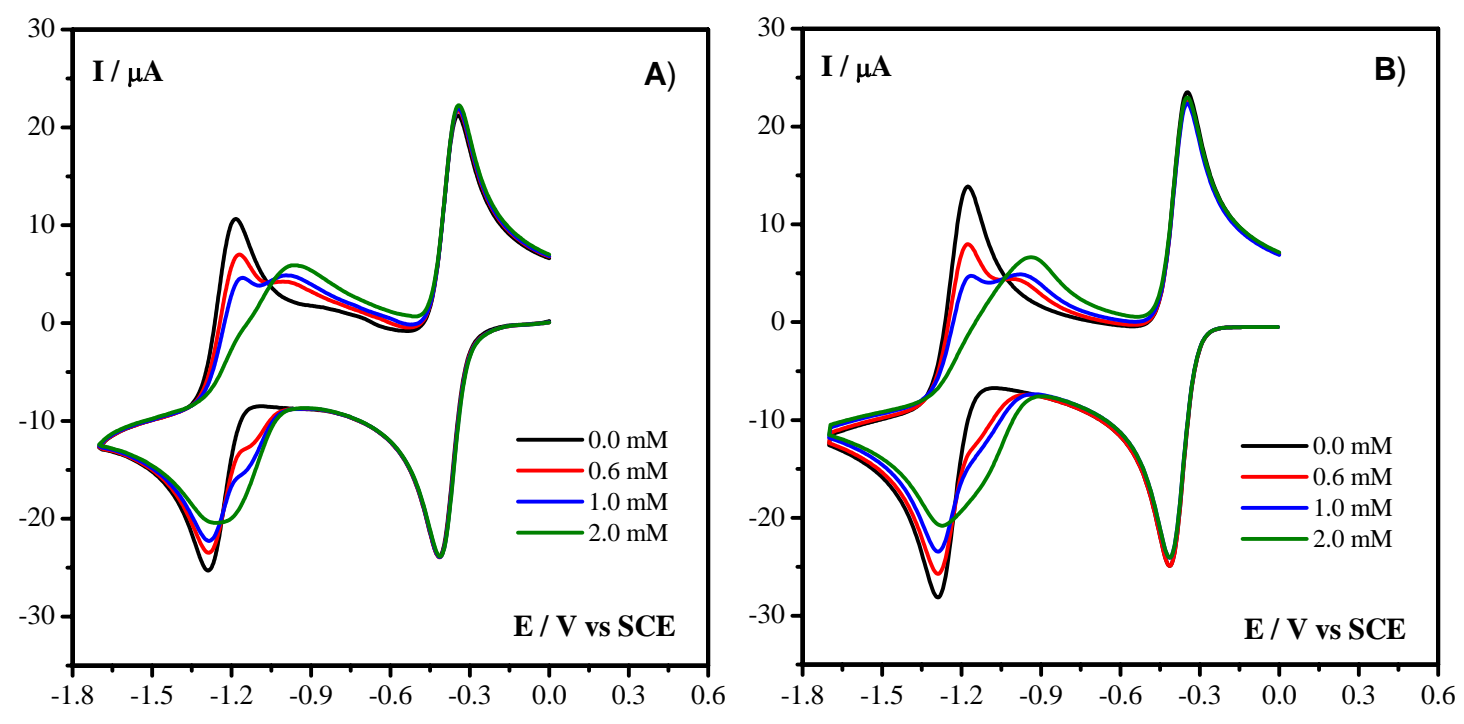

Figure 2. Cyclic voltammetry of 1,4-benzoquinone $2 \mathrm{mM}$, in $\mathrm{DMSO}+0.2 \mathrm{M} n-\mathrm{Bu}_{4} \mathrm{NPF}_{6}$, on glassy carbon electrode (3 $\mathrm{mm} \phi)$, at $0.1 \mathrm{Vs}^{-1}$, at different concentrations of $\mathrm{CH}$. A) Experimental curves, B) simulated curves. 
Table 1. Thermodynamic and kinetic parameters ${ }^{\text {a) }}$ obtained from the simulation of the reduction and association steps involved in the mechanism depicted in Scheme 1

\begin{tabular}{llllll}
\hline$E_{1}^{0}(\mathrm{~V} / \mathrm{SCE})$ & $k_{\mathrm{s} 1}\left(\mathrm{~cm} \mathrm{~s}^{-1}\right)$ & $E_{2}^{0}(\mathrm{~V} / \mathrm{SCE})$ & $k_{\mathrm{s} 2}\left(\mathrm{~cm} \mathrm{~s}^{-1}\right)$ & $E_{6}^{0}(\mathrm{~V} / \mathrm{SCE})$ & $k_{\mathrm{s} 6}\left(\mathrm{~cm} \mathrm{~s}^{-1}\right)$ \\
\hline-0.38 & 0.02 & -1.231 & $0.0025-0.003$ & $0.946-0.948$ & $0.01-0.013$ \\
$K_{3}\left(\mathrm{M}^{-1}\right)$ & $k_{3}\left(\mathrm{M}^{-1} \mathrm{~s}^{-1}\right)$ & $K_{4}\left(\mathrm{M}^{-1}\right)$ & $k_{4}\left(\mathrm{M}^{-1} \mathrm{~s}^{-1}\right)$ & $K_{5}\left(\mathrm{M}^{-1}\right)$ & $k_{5}\left(\mathrm{M}^{-1} \mathrm{~s}^{-1}\right)$ \\
5 & $>1 \times 10^{6}$ & $2.8-3.0 \times 10^{5}$ & $1 \times 10^{10}$ & $1250-2500$ & $1 \times 10^{10}$ \\
\hline
\end{tabular}

${ }^{\mathrm{a}} \mathrm{E}^{\mathrm{o}}=$ formal potential, $k_{\mathrm{s}}=$ standard rate constant of electron transfer, $K=$ association equilibrium constants, $k=$ association forward kinetic constants.

The data collected in Table 1 show a small value of $K_{3}$ which is in accord with a very weak interaction between $\mathrm{Q}^{-}$and $\mathrm{CH}$, and which in cyclic voltammetry is manifested trough the marginal variation of the half-wave potential of wave I-II with the concentration of $\mathrm{CH}$. Similarly, the high value of $K_{4}$ indicates that the first association process between $\mathrm{Q}^{2-}$ and $\mathrm{CH}$ is very strong. This association occurs on one of the negative oxygen atoms of $\mathrm{Q}^{2-}$ and must diminish the electron density on the opposite free oxygen atom, which provokes that the association step between $\mathrm{Q}^{2-}(\mathrm{CH})$ and $\mathrm{CH}$ be weaker than the first one $\left(K_{4}>>K_{5}\right)$.

\section{Reduction of 1,4-benzoquinone (Q) in the presence of 9-ethylguanine (GH)}

In this section, the interaction between the reduced species of benzoquinone with the nucleobase 9-ethylguanine $(\mathrm{GH})$ is analyzed. From the molecular recognition point of view, GH is complementary to the nucleobase $\mathrm{CH}$. Figure 3a shows the typical behavior of $\mathrm{Q}$ in aprotic medium (DMSO), which exhibits oxido-reduction waves (I-II and III-IV) corresponding to the redox pairs $\mathrm{Q} / \mathrm{Q}^{-{ }^{-}}$and $\mathrm{Q} \cdot{ }^{-} / \mathrm{Q}^{2-}$ respectively (eqs. 1 and 2). ${ }^{16,17}$ When an excess of $\mathrm{GH}$ is present, it is observed the disappearance of wave III-IV and the modification of wave I into wave I', which is chemically irreversible and presents a current intensity that is two-fold the current of wave I.

As in the typical reduction process of quinones in acidic medium, ${ }^{26,27}$ this result suggests that the reduction mechanism at the level of wave I' involves electron and proton transfer reactions, which can be considered to occur in the framework of an Electrochemical-ChemicalElectrochemical (ECE) mechanism (eqs. 7-9), in competition with a first or second order disproportionation (DISP1 or DISP2) mechanism (eqs 7, 8, 10). ${ }^{28}$ 


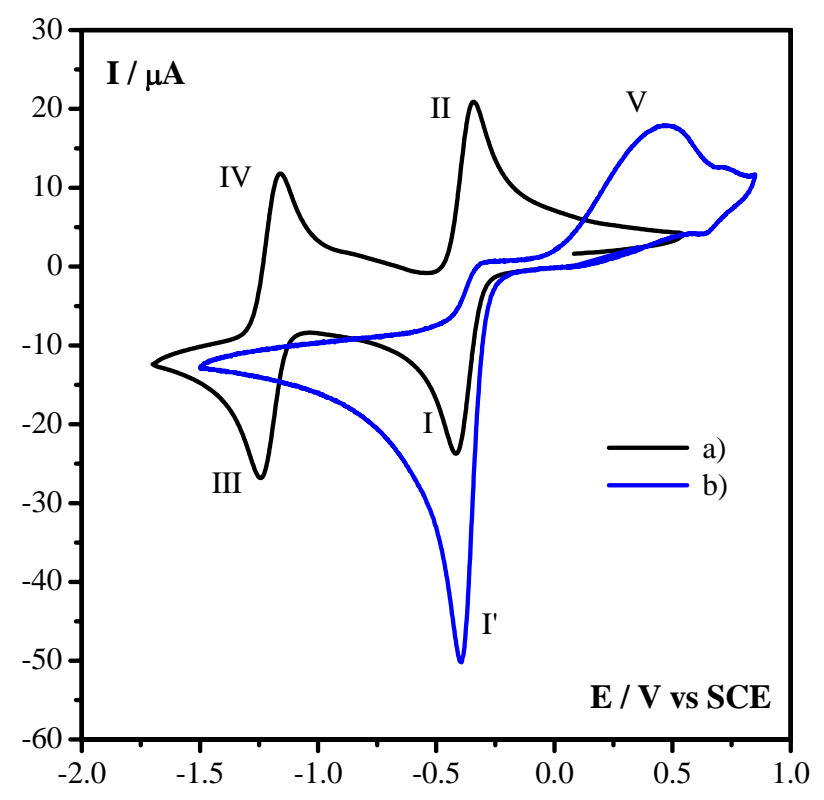

Figure 3. Cyclic voltammetry of 1,4-benzoquinone $2 \mathrm{mM}$, in $\mathrm{DMSO}+0.2 \mathrm{M} n-\mathrm{Bu}_{4} \mathrm{NPF}_{6}$, on glassy carbon electrode ( $3 \mathrm{~mm} \phi$ ), at $0.1 \mathrm{Vs}^{-1}$, at different concentrations of 9-ethylguanine: a) $0 \mathrm{mM}$, b) $50 \mathrm{mM}$.

$$
\begin{aligned}
& \mathrm{Q}+\mathrm{e}^{-} \stackrel{\mathrm{E}_{7}^{\mathrm{o}}}{\rightleftharpoons} \mathrm{Q}^{\cdot-} \\
& \mathrm{Q}^{\cdot^{-}}+\mathrm{GH} \stackrel{\mathrm{K}_{8}}{\rightleftharpoons} \mathrm{QH} \cdot \mathbf{G}^{-} \\
& \mathrm{QH} \cdot+\mathrm{e}^{-} \stackrel{\mathrm{E}_{9}^{0}}{\rightleftharpoons} \mathrm{QH}^{-} \\
& \mathrm{QH} \cdot+\mathrm{Q}^{--} \stackrel{\mathrm{K}_{\mathrm{d}}}{\rightleftharpoons} \mathrm{QH}^{-}+\mathrm{Q} \\
& \mathrm{Q}+2 \mathrm{e}^{-}+\mathbf{G H}=2 \mathrm{QH}^{-}+\mathbf{G}^{-}
\end{aligned}
$$

According to these mechanisms, benzoquinone $\mathrm{Q}$ is reduced to generate the semiquinone $\mathrm{Q}^{-}$, which is then protonated to afford the radical $\mathrm{QH}$. The occurrence of this protonation reaction confers chemical irreversibility to signal I'. After this, the radical $\mathrm{QH}^{\cdot}$ is reduced to generate the anion $\mathrm{QH}^{-26,27}$ via an heterogeneous (eq. 9) or homogeneous (eq. 10) reaction. These steps are consistent with the two-electron character of wave I', and the global electronic stoichiometry (eq. 11), which result from either the reaction pathways $7+8+9$ or $7+8+10$. As in the previous study with 1-octylthymine, ${ }^{15}$ the anion $\mathrm{QH}^{-}$can be stabilized by association with $\mathrm{GH}$ (present in excess in the solution), to afford the complex $\mathrm{QH}^{-}(\mathrm{GH})$, which is oxidized at the 
potential of wave $\mathrm{V}$ (Figure 3b). ${ }^{15}$ Although the oxidation wave of hydroquinone $\left(\mathrm{QH}_{2}\right)$ was not observed, it could be expected under longer periods of time.

The predominance of pathways (ECE) or (DISP1 or DISP2), depends mainly on the rate of the protonation reaction $8,{ }^{28}$ which can be assumed to be slow since the partial reversibility of wave I' is achieved at scan rates higher than $5 \mathrm{Vs}^{-1}$ (wave II). Consequently, the occurrence of either the mechanism DISP1 or DISP2 is clear. In this regard, the analysis of the variation of the peak potential of wave I' with respect to the scan rate allow the discrimination between these mechanisms.

Figure $4 \mathrm{~A}$ and $4 \mathrm{~B}$ show, the effect of scan rate on both the voltammetric behavior and the peak potential I' respectively. In Figure 4B, it is observed that the variation of the peak potential is linear until $5 \mathrm{Vs}^{-1}$ and it tends to be constant at higher scan rates. Thus, it can be concluded that the mechanism is operative DISP2 since the slope of the linear portion $(20.8 \mathrm{mV} / \mathrm{dec}$.) is close to the theoretical value of $19 \mathrm{mV} / \mathrm{dec}$. predicted for this mechanism at $25{ }^{\circ} \mathrm{C} .{ }^{28}$

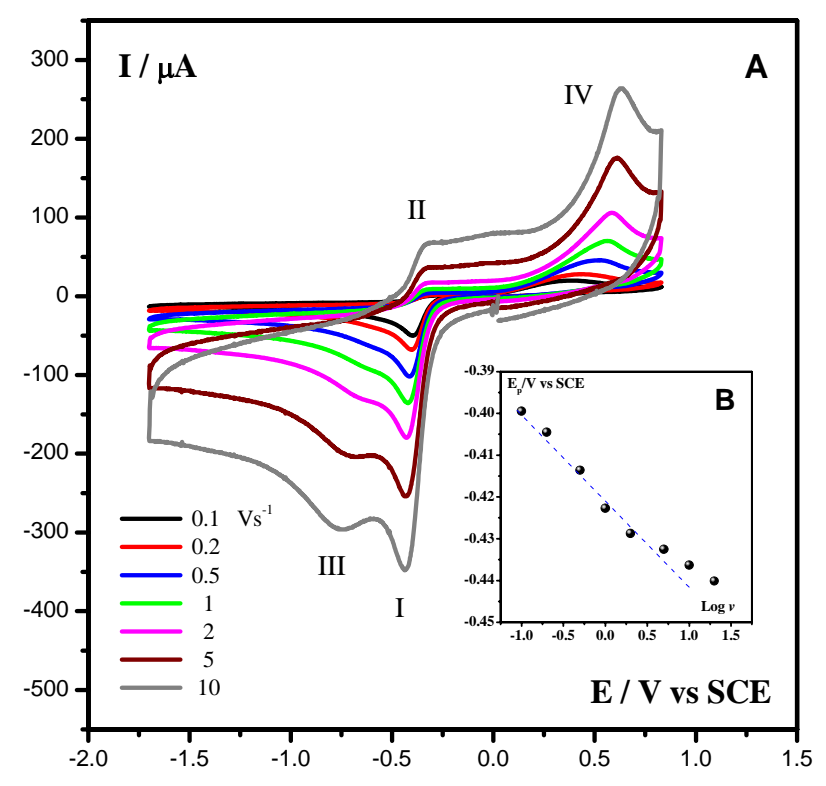

Figure 4. Cyclic voltammetry of 1,4-benzoquinone $2 \mathrm{mM}$, in presence of 9-ethylguanine 50 $\mathrm{mM}$, in $\mathrm{DMSO}+0.2 \mathrm{M} n-\mathrm{Bu}_{4} \mathrm{NPF}_{6}$. A) Voltammograms at different scan rates. B) Variation of the peak potential I with the scan rate.

Concerning the voltammetric behavior at high scan rates, Figure 4A shows that wave IV, corresponding to the oxidation of $\mathrm{QH}^{-}(\mathrm{GH})$, is intense, which means that this complex must be formed by an alternative mechanism, but now occurring at the level of wave III. That is, the new reaction pathway does not include the protonation of $\mathrm{Q}^{-}$, because this slow reaction has no opportunity to occur at high scan rates. Taking into account that the electrochemical behavior of systems such as benzoquinone/1-octylthymine, at slow scan rates, ${ }^{15}$ is similar to that found for 9- 
ethylguanine at high scan rates, the reduction mechanism occurring at the level of wave III can be described as follows.

In wave $\mathrm{I}$, the benzoquinone $\mathrm{Q}$ is reduced to the corresponding semiquinone $\mathrm{Q}^{-}$(eq. 7). Due to the weakly basic character of $\mathrm{Q}^{-}$, it participates in an association equilibrium with $\mathrm{GH}$ which must be thermodynamically unfavored but kinetically very fast (eq. 12). Hence a small fraction of the complex $\mathrm{Q}^{-}(\mathrm{GH})$ is generated at the level of wave I and this species is next reduced at the level of wave III following a concerted electron and proton transfer process as depicted by equation $13 .{ }^{15,29}$ The proposal of this concerted reaction is based on the fact that wave III is quite large (the variation of the peak potential with the scan rate is about 170 $\mathrm{mV} /$ dec.) and presents a value of peak potential which is less negative with respect to wave II $\left(\mathrm{E}_{\mathrm{pIII}}-\mathrm{E}_{\mathrm{pII}}>>300 \mathrm{mV}\right) .^{30}$ As it has been mentioned before, the product $\mathrm{QH}^{-}$must be stabilized by hydrogen bonding with excess of GH present in the solution. ${ }^{15}$

$$
\begin{aligned}
& \mathrm{Q}^{\cdot^{-}+\mathbf{G H}} \rightleftharpoons \mathrm{Q}^{\cdot^{-}}(\mathbf{G H}) \\
& \mathrm{Q}^{\cdot-}(\mathbf{G H})+\mathrm{e}^{-} \longrightarrow \mathrm{QH}^{-}+\mathbf{G}^{-}
\end{aligned}
$$

As in the case of the mechanism DISP2 obtained at slow scan rates (eqs. 7, 8 and 10), the sequence of reactions 7, 12 and 13, presents also a two-electron stoichiometry, but now, at the level of wave III. Considering that in both two-electron mechanisms the species $\mathrm{G}^{-}$is formed, in the next section the participation of this specie in reactions occurring at longer scales of time such as that corresponding to electrolysis experiments is studied.

\section{Electrolysis of the 1,4-benzoquinone (Q) in presence of 9-ethylguanine (GH)}

The role of $\mathrm{G}^{-}$on the global mechanism of reaction DISP2 can be directly established by means of coulommetry. In this experiment, it is expected a charge consumption equivalent to an electron number of two (eq. 11), however; if there exists a slow parallel processes consuming Q, this number would be lower than two. Figure 5A shows a plot of the charge consumed during the electrolysis of $\mathrm{Q}$ at different times of total electrolysis, which were controlled by using different working electrodes of different area upon similar stirring regimes. It is observed that an increase in the time of electrolysis is accompanied by a decrease of the electron number ( $\left.\mathrm{n}_{\mathrm{app}}\right)$. This result suggests the participation of an alternative process consuming Q during the electrolysis. In this process, some of the probable reaction products generated in the mechanism DISP2 must be involved; $\mathrm{G}^{-}, \mathrm{QH}^{-}(\mathrm{GH}), \mathrm{QH}_{2}$. The cyclic voltammetry obtained after total electrolysis of $\mathrm{Q}$ (Figure 5B), showed that $\mathrm{QH}^{-}(\mathrm{GH})$ (wave II) is formed mainly with a fraction of $\mathrm{QH}_{2}$ (wave III). As it has been mentioned before, this means that the complex $\mathrm{QH}^{-}(\mathrm{GH})$ could be the precursor of $\mathrm{QH}_{2}$. 

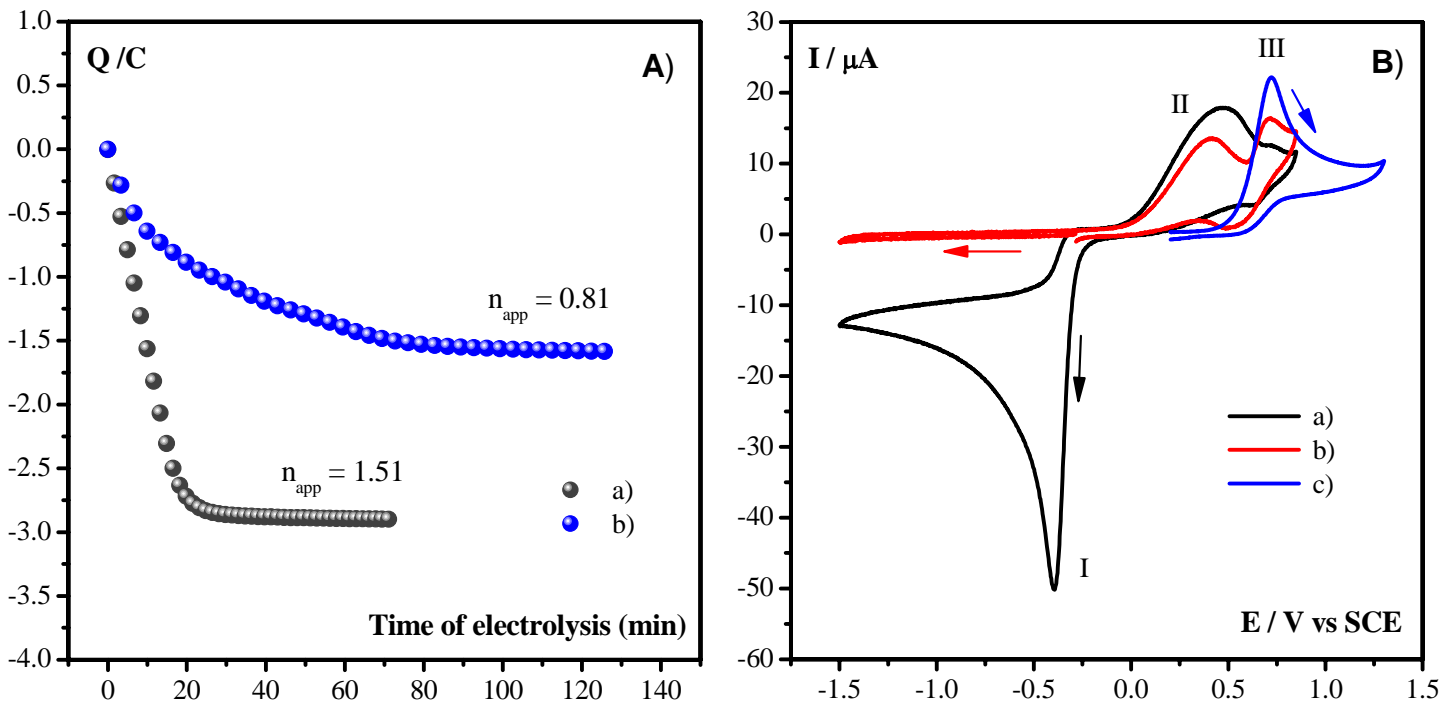

Figure 5. Electrolysis of 1,4-benzoquinone $2 \mathrm{mM}$ in presence of 9-ethylguanine $50 \mathrm{mM}$, in DMSO +0.2 $\mathrm{M} n-\mathrm{Bu}_{4} \mathrm{NPF}_{6}$. A) Coulommetry on; a) reticulated glassy carbon, b) glassy carbon rod. B) Cyclic voltammetry at $0.1 \mathrm{Vs}^{-1}$; a) before the electrolysis, b) after the electrolysis, c) hydroquinone.

Considering that during the protonation processes the highly nucleophilic anion $\mathrm{G}^{-}$is generated, the intervention of a reaction between $\mathrm{G}^{-}$and the neutral benzoquinone $\mathrm{Q}$ is likely. In order to verify the existence of this time depending reaction, the reduction wave of $Q$ in the presence of an excess of $\mathrm{GH}$ and a small amount of $\mathrm{G}^{-}$was monitored (Figure 6).

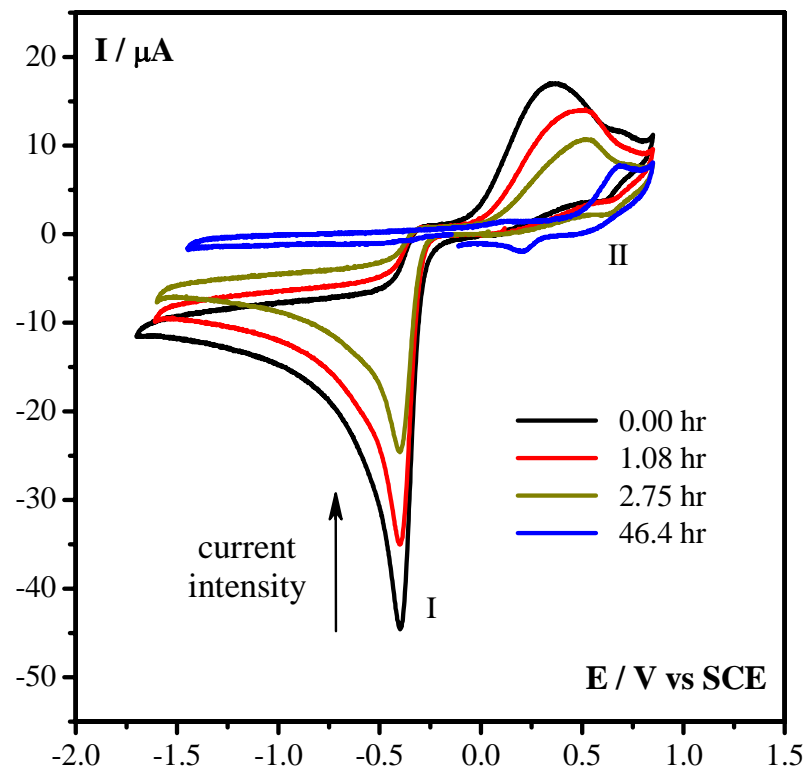

Figure 6. Cyclic voltammetry of 1,4-benzoquinone $1 \mathrm{mM}+\mathrm{GH} 19.5 \mathrm{mM}+\mathrm{G}^{-} 0.5 \mathrm{mM}$, in $\mathrm{DMSO}+0.2 \mathrm{M} \mathrm{n}-\mathrm{Bu}_{4} \mathrm{NPF}_{6}$, at $0.1 \mathrm{~V} \mathrm{~s}^{-1}$. Variation of the peak current $\mathrm{I}$ as a function of time. 
In this figure, the decrease of the current peak I (proportional to the concentration of Q) is observed, which confirms the presence of a reaction between $\mathrm{Q}$ and $\mathrm{G}^{-}$. A likely mechanism of reaction between $\mathrm{Q}$ and $\mathrm{G}^{-}$, is the 1,4 type Michael oxidative addition. ${ }^{2}$ However, this reaction was discarded by considering that the ${ }^{13} \mathrm{C}-\mathrm{NMR}$ spectra of the reaction product showed only the presence of signals corresponding to hydroquinone $\mathrm{QH}_{2}$ (116.20 ppm and $\left.150.28 \mathrm{ppm}\right)$. The formation of this compound was also verified by gas chromatography coupled with mass spectrometry (m/z: 110, 81, 53). In agreement with this proposal, in figure 6 the wave II is located approximately at the same peak potential of pure hydroquinone (wave III in figure 5B). An alternative reaction that was considered is the redox process between $Q$ and $\mathrm{G}^{-}$, which should afford semiquinone and a radical $\mathrm{G}$ : Considering that an excess of $\mathrm{GH}$ is present in the solution, the semiquinone should be protonated affording $\mathrm{QH}$. This species is then reduced and protonated to generate $\mathrm{QH}_{2}$. Each protonation reaction regenerates $\mathrm{G}^{-}$, which participates once again in other redox process. According to this proposal, $\mathrm{G}^{-}$reacts with $\mathrm{Q}$ following a homogeneous catalytic pathway, which is in agreement with the fact that only a small fraction of $\mathrm{G}^{-}$is necessary to initiate the slow transformation of $\mathrm{Q}$ into $\mathrm{QH}_{2}$. Although we have not definitive evidence about the product derived from $\mathrm{G}^{3}{ }^{32}$, the results presented here allow to propose that the radical destruction of guanine could be initiated by the reduction of only some molecules of $\mathrm{Q}$. This behavior is similar to that found in the case of the nucleobase 1 -octylthymine, ${ }^{15}$ and could be relevant to explain the cytotoxic effect of quinones on pyrimidines and purines of biological importance.

\section{Conclusions}

Reduced species of 1,4-benzoquinone (Q) interact with the alkylated nucleobases 1-octylcytosine $(\mathrm{CH})$ and 9-ethylguanine $(\mathrm{GH})$ by means of hydrogen bonding and/or protonation processes. The nucleobase $\mathrm{CH}$ interacts weakly with semiquinone $\left(\mathrm{Q}^{-}\right)$and strongly with the dianion $\left(\mathrm{Q}^{2-}\right)$. This interaction takes place by hydrogen bonding between the $\mathrm{NH}_{2}$ group of $\mathrm{CH}$ and the negatively charged oxygen atoms of the reduced species of Q. This behavior is analogous to that reported for 9-octyladenine. ${ }^{15}$

Alternatively, the nucleobase 9-ethylguanine induces an electron and proton transfer mechanism DISP2, which is activated by the protonation of the electrochemically generated semiquinone. This reaction is slow and its inhibition at high scan rates in cyclic voltammetry, leads to a modification of the mechanism which involves the concerted protonation and reduction of an association complex formed between semiquinone and the nucleobase $\mathrm{Q} \cdot{ }^{-}(\mathrm{GH})$. The $-\mathrm{NH}$ group is responsible of the proton transfer reaction observed for $\mathrm{GH}$, generating $\mathrm{G}^{-}$. The conjugated base $\mathrm{G}^{-}$participates as reductor of the neutral quinone $\mathrm{Q}$. This redox reaction induces the catalytic self-consumption of $\mathrm{Q}$ and $\mathrm{GH}$. This process is similar to that found in the case of 1-octylthymine (TH); however, it is less efficient due to the fact that $\mathrm{G}^{-}$oxidizes with more difficulty than $\mathrm{T}^{-}$. 


\section{Experimental Section}

General Procedures. Tetrabutylammonium hexafluorophosphate $98 \%\left(n-\mathrm{Bu}_{4} \mathrm{NPF}_{6}\right)$, tetrabutylammonium hydroxide $1 \mathrm{M}$ in methanol, hydroquinone 99\%, 1,4-benzoquinone $99 \%$ and 9-ethylguanine were Aldrich chemicals. The 1,4-benzoquinone was purified by sublimation under vacuum. Dimethylsulfoxide (DMSO) spectral grade was used as the solvent. The 1octylcytosine $(\mathrm{CH})$ was prepared from the corresponding nucleobase and 1-bromooctane, according to a general procedure previously reported. ${ }^{31}$

Cyclic voltammetry and coulommetry experiments were performed with a Radiometer potentiostat DEA332 with positive feedback resistance compensation. A three-electrode cell was used in the electrochemical experiments. The working electrode was a $3 \mathrm{~mm}$ diameter glassy carbon disk, which was polished with $1 \mu \mathrm{m}$ alumina powder and ultrasonically rinsed with ethanol before each run. The counter electrode was a platinum screen and the reference was an aqueous saturated calomel electrode (SCE). A salt bridge, containing a solution of the supporting electrolyte and DMSO, connected the cell with the reference electrode. All electrochemical experiments were performed at $25^{\circ} \mathrm{C}$ under an argon atmosphere. The digital simulation of the voltammetric curves was carried out with the program DigiSim 2.1, from Bioanalytical Systems Inc.

\section{Acknowledgements}

The authors acknowledge Conacyt for financial support through the projects G32710-E and 32221-E.

\section{References and notes}

1. Cramer, W. A.; Knaff, D. B. In Energy Transduction in Biological Membranes; Cantor, C. R. Ed.; Springer-Verlag: New York, 1990; Ch. 4.

2. Patai S. The Chemistry of the Quinoid Compounds; Wiley: New York, 1988; Ch. 13.

3. Stryer L. Biochemistry; Freeman H. Co.: San Francisco, 1981; Ch. 14.

4. Anthony, C. Biochem. J. 1996, 320, 697.

5. Monks, T. J.; Hanzlik, R. P.; Cohen, G. M.; Ross, D.; Graham, D. G Toxicol. Appl. Pharmacol. 1992, 112, 2.

6. Alegria, A. E.; Cordones, E.; Santiago, G.; Marcano, Y.; Sanchez, S.; Gordaliza, M.; Martin-Martin, M. L. Toxicol. 2002, 175, 167.

7. Assimopoulou, A.N.; Boskou, D.; Papageorgiou, V.P. Food Chem. 2004, 87, 433.

8. Papageorgiou, V.P.; Assimopoulou, A.N.; Coladourus, E.A.; Hepworth, D.; Nicolaou, K.C.; Angew. Chem. Int. Ed. 1999, 38, 270. 
9. Lin, A. J.; Sartorelli, A. C. Biochem. Pharmacol. 1976, 25, 206.

10. Cheng, Z.; Cheng, C. C. J. Med. Chem. 1978, 21, 291.

11. Lin, A. J.; Sartorelli, A. C. J. Org. Chem. 1973, 38, 813.

12. Schrebler, R. S.; Arratia, A.; Sánchez, S.; Haun, M.; Durán, N. J. Electroanal. Chem. 1990, 298, 81.

13. Wagner, J. R.; Van Lier, J. E.; Johnston, L. J. Photochem. Photobiol. 1990, 52, 333.

14. Roth.; H. D.; Lamola, A. A. J. Am. Chem. Soc. 1972, 94, 1013.

15. Salas, M.; Gómez, M.; González, F. J.; Gordillo, B. J. Electroanal. Chem. 2003, 543, 73.

16. Eggins, B. R.; Chambers, J. Q. J. Electrochem. Soc. 1970, 117, 186.

17. Patai, S.; Rappoport, Z., The Chemistry of the Quinoid Compounds, Wiley: New York, 1998; Vol. 2, Part 2, Ch. 12.

18. Gómez, M.; Gómez-Castro, C. Z.; Padilla-Martínez I. I.; Martínez-Martínez, F. J.; González, F. J. J. Electroanal. Chem. 2004, 567, 269.

19. Gómez, M.; González, F. J.; González, I. J. Electrochem. Soc. 2003, 150, E527

20. Gupta, N.; Linschitz, H. J. Am. Chem. Soc. 1997, 119, 6384.

21. Uno, B.; Okomura, N. ; Goto, M.; Kano, K. J. Org. Chem. 2000, 65, 1448.

22. Gomez, M.; González, F. J.; González, I. Electroanal. 2003, 15, 635.

23. Rudolph, M.; Reddy, D. P.; Feldberg, S. W. Anal. Chem. 1993, 66, 589A

24. Boulas, P. L.; Gómez-Kaifer, M.; Echegoyen, L. Angew. Chem. Int. Ed. 1998, 37, 216.

25. Bautista, J. A.; González I.; Aguilar, M. J. Electroanal. Chem. 2004, 573, 289.

26. González, F. J. Electroanal. 1998, 10, 638.

27. Aguilar-Martínez, M.; Macías-Ruvalcaba, N. A.; Bautista-Martínez, J. A.; Gómez, M.; González, F. J.; González, I. Curr. Org. Chem. 2004, 8, 1721.

28. Amatore, C.; Savéant, J-M. J. Electroanal. Chem. 1977, 85, 27

29. Lehmann, M. W.; Evans, D. H. J. Phys. Chem. B. 2001, 105, 8877.

30. Savéant, J-M. Advances in Physical Organic Chemistry 2000, 35, 117.

31. Vorbrüggen, H.; Krolikiewicz, K.; Bennua, B. Chem. Ber. 1981, 114, 1234.

32. Attempts of purification of the product derived from $G$ ' were unsuccessful because of the small amount of sample used in the experiments. However, peaks of $\mathrm{m} / \mathrm{z}=356 \mathrm{and} \mathrm{m} / \mathrm{z}=$ 110 , that confirm the presence of a dimmer G-G and hydroquinone respectively, were observed in the mass spectra of the raw product. 